\title{
A GEOGRAFIA NO CONTEXTO DAS CIÊNCIAS SOCIAIS EM PERNAMBUCO*
}

\section{Manuel Correia de Andrade}

\section{O objeto de reflexão}

Estabelecendo o objeto de reflexão, procuramos delimitar no espaço e no tempo o que seria a Geografia e quais as relações por ela mantidas com as várias ciências naturais e sociais que lhe estão próximas e que, muitas vezes, se interpenetram.

Levaremos em conta que uma ciência não pode ser contida dentro de um estado ou de um país, em face da coexistência de princípios gerais, comuns às várias regiões, e aqueles restritos a uma região ou até a um estado.

O conhecimento científico não é limitado no tempo, devido à própria evolução do processo de

* Agradeço a Thais Correia de Andrade a cessão do texto inédito e a Silke Weber pela intermediação para a publicação neste periódico [N.E.]

Artigo recebido e aprovado em agosto/2007 apropriação do espaço, da evolução dos processos de reflexão e do avanço tecnológico. Não se pode esquecer também que o processo está em mudança constante e que o conhecimento já armazenado vai absorvendo novos conhecimentos, assimilando-os e transformando-se. E, se o conhecimento necessita ser transformado continuamente, ele não prescinde da produção do passado para absorver o novo sem nenhuma vinculação anterior.

Daí, a grande importância da universidade como Casa, ao mesmo tempo, de produção e transmissão de conhecimento, de estância, onde se procura comparar as experiências importadas de outras nações, examinando quando e como devem ser assimiladas ou rejeitadas.

No caso da Geografia, que se expandiu e despertou grande interesse no século XIX, ela se apresentou muito dependente das divisões político-administrativas e muito preocupada com o mais variado acervo de informações que a trans- 
formavam em um verdadeiro almanaque. Era o caso das famosas Corografias do Brasil, nas quais os estados eram enumerados em série, de acordo com a localização geográfica e, muitas vezes, com os acidentes geográficos colocados de acordo com a ordem alfabética. A geografia fornecia informações, mas não formava os caracteres, eram quase catálogos.

\section{O processo de transformação}

No Brasil de um modo geral, e em Pernambuco em particular, o processo de transformação do conhecimento geográfico ocorreu a partir, sobretudo, do início do século XX, com estudos, nem sempre considerados geográficos, mas que abordavam temas referentes ao processo de renovação da organização do espaço. E, naquela ocasião, podemos citar os trabalhos de alguns estudiosos que marcaram sensivelmente a problemática, congregando o geográfico ao natural, ao político e ao social. São deste período, em Pernambuco, os numerosos estudos do historiador Pereira da Costa que, analisando a evolução do estado, fez observações diretas sobre o arquipélago de Fernando de Noronha, estudos detalhados sobre a evolução da cidade do Recife e dos seus arredores, assim como sobre as questões de limites do estado de Pernambuco com províncias e estados vizinhos.

Merecem referências, também, os livros de Artur Orlando, Porto e cidade do Recife, publicado em 1908, e Brasil, a terra e o bomem, de 1912. No primeiro, ele analisa a localização e a importância do Recife na ocasião em que eram concluídas as obras de modernização do porto, procurando projetá-lo como o principal porto do Brasil e da América, no Atlântico Sul - o mais próximo da África e da Europa - e, para caracterizar a importância da cidade, fez uma análise, aprofundada para a época, das condições de relevo, de solo, do clima da região dele dependente, comparando com as observadas em outros continentes. E procurou mostrar como estas condições tinham influência sobre o que chamamos, hoje, de "qualidade de vida” da população. No segundo, o autor já encara o país de forma mais ampla, talvez influenciado pelas idéias de Elisée Reclus e de Pierre Denis, de vez que já, em 1890, havia sido traduzido para o português e publicado no nosso país a parte da Geografia Universal referente ao então Estados Unidos do Brasil e, em Portugal, o livro do Pierre Denis O Brasil no século $X X$, que dava grande importância às atividades econômicas na interpretação do espaço geográfico.

Mantendo uma certa fidelidade à "velha" geografia, atuou na imprensa pernambucana, durante décadas, o historiador Mario Melo, que publicou uma Corografia de Pernambuco e uma Hidrografia, também de Pernambuco, listando acidentes geográficos por ordem alfabética e chamando de "cordilheiras" a formação montanhosa de porte modesto que se erguia sobre o maciço da Borborema. Eram, porém, contribuições muito válidas para a época em que foram publicadas.

Em 1921, surgiu um livro marcante, a tese com que o político, Agamenon Magalhães, disputou a cadeira de Geografia Geral do Ginásio Pernambucano. Tese em que procurou caracterizar o Nordeste brasileiro, baseando-se nos ensinamentos dos mestres franceses de então: Vidal de la Blache, Camille Vallaux, Jean Brunhes. Foram discípulos desses mestres, Pierre Deffontaines, Pierre Mombeig e Francis Ruellan, que revolucionaram a geografia brasileira nos anos de 1940, introduzindo o que se convencionou chamar de geografia moderna, ou científica.

O grande impacto sobre a geografia pernambucana e brasileira, porém, foi causado, nos anos de 1920 e 1930 pelo antropólogo Gilberto Freyre que, após cursos de graduação e de mestrado nos Estados Unidos e viagens de contatos e pesquisas na Europa, voltou ao Brasil e procurou revolucionar, a partir da cidade do Recife, a forma de ver e de sentir o país e a região. Ele trouxe como novidade científica as idéias de regionalismo, de tradicionalismo - sem que a tradição confrontasse a modernização -, de ecletismo cultural e religioso e preocupações ecológicas. Idéias que lhe foram transmitidas, em grande parte, por Boas, seu mestre em Columbia, e ele próprio um grande conhecedor da geografia. Entre os seus livros famosos, pode-se destacar Nordeste, no qual estuda a forma como a cultura da cana-deaçúcar avançou pela porção oriental da região, destruindo a Mata Atlântica, sua fauna e flora, poluindo os rios e organizando a posse e a propri- 
edade da terra, com base em uma sociedade patriarcal, e procurava também diferenciar, no Nordeste, a região úmida da semi-árida, do Sertão, como se dizia então.

Posteriormente, estendendo suas pesquisas à Índia e à África, Freyre desenvolveu um ramo de conhecimento a que chamou de Luso Tropicologia, onde procurava mostrar como o colonizador lusitano apossou-se das terras tropicais, fundando civilizações não européias e não africanas ou asiáticas. Na verdade, nessas análises ele demonstrava uma certa simpatia pela colonização portuguesa, tão combatida por sociólogos e historiadores dos vários pontos do país.

Notável, também, foi a contribuição do botânico João Vasconcelos Sobrinho à formação da geografia pernambucana, de vez que, iniciando os estudos de botânica sistemática, ele passou à análise das associações vegetais chocando-se com o avanço da destruição da floresta Atlântica. Em seguida, estendeu seus estudos por outras associações vegetais do Nordeste e escreveu, em 1950, um livro sobre Pernambuco e, em 1971, um outro sobre o Nordeste. Neste, sua obra principal, As regiões naturais, o meio e a civilização do Nordeste, começa com um capítulo sobre o que denominou Geografia Ecológica, dando grande importância à ciência geográfica e à sua abrangência em associação com outras ciências afins. Trabalhador $\mathrm{e}$ empolgado com os estudos que desenvolvia, Vasconcelos formou discípulos, como o fito-geógrafo Dárdano de Andrade Lima, e batalhou, como militante, em favor de uma política que hoje chamamos de preservação do meio ambiente, dando uma grande importância ao rio São Francisco que, segundo ele, se encontrava com forte perda de seu volume d'água, podendo, com o tempo, tornar-se um rio temporário. Faleceu antes de presenciar as grandes transformações ocorridas neste rio, após a construção de numerosas barragens.

\section{Os primeiros geógrafos e o estímulo desenvolvido pelos colégios oficiais}

Os anos de 1930 foram iniciados com a conversão do médico, Josué de Castro, em geógrafo, de vez que, dedicando-se, como médico, aos estudos ligados à alimentação e fazendo pesquisas em áreas habitadas por pessoas pobres, inclusive nos mocambos do Capibaribe, no Recife, foi levado a fazer estudos de Geografia e, em seguida, a lecionar Antropologia e Geografia Humana na Universidade do Distrito Federal, no Rio de Janeiro. Escreveu livros como A alimentação brasileira à luz da geografia bumana, Documentário do Nordeste e Geografia bumana e, em seguida, já famoso, escreveu a Geografia da fome e a Geopolitica da fome. Como político, foi deputado federal por duas legislaturas e membro da diretoria da FAO, em Roma. Tendo idéias favoráveis à reforma agrária, à alfabetização intensa e à melhoria das condições de vida da população de baixa renda, foi cassado após o golpe de 64 e radicouse em Paris como professor da Universidade de Vincennes. Sua grande contribuição cientifica está em ter analisado o problema da fome no Brasil, dividindo o país em cinco regiões alimentares e constatando que na maior parte do território ocorria fome, ora de forma endêmica, ora de forma epidêmica, o que tinha como causas, ora condições naturais, caso da Amazônia, ora as estruturas econômico-sociais, caso do Nordeste úmido, açucareiro.

A divulgação das obras dos geógrafos franceses e alemães deu margem ao surgimento, na década de 1930, de livros didáticos modernos, escritos, no Rio de Janeiro, por Delgado de Carvalho, e, em São Paulo, por Aroldo de Azevedo, substituindo os velhos textos que valorizavam, sobretudo, a memorização. Também os cursos ministrados na Universidade de São Paulo e do Distrito Federal, divulgaram mais os conhecimentos de geografia em nível científico e contribuíram para um melhor conhecimento da ciência geográfica. Isto se refletiu na produção das teses para preenchimento das cátedras dos colégios estaduais, disputadas por professores que lecionavam no ensino secundário ou ocupavam cargos na administração pública.

Em 1939, ocorreu a abertura do concurso para catedrático do Ginásio Pernambucano, colégio tradicional, fundado no início do Segundo Reinado, nele se inscrevendo três jovens professores formados em Direito: Gilberto Osório de Andrade, com tese sobre A Amazônia, um complexo antropogeográfico, Mário Lacerda de Mello, com Pernambuco, traços da geografia bumana e José Alfredo de Menezes, com um estudo sobre 
variações climáticas. Teses que abordavam temas dentro dos parâmetros da época e cuidadosamente organizadas de acordo com os ensinamentos de Jean Brunhes, de De Martone e de Vidal de la Blache. Passara o período de maior influência de Elisée Reclus e de Pierre Denis.

Os estudos geopolíticos desenvolveram-se, no país, com Everaldo Backhaus, com maior divulgação nos meios militares e nos órgãos que norteavam a política nacional. O concurso de 1939 não se realizou, em vista do período conturbado do Estado Novo; no período democrático, nos anos de 1950, porém, concursos foram abertos e realizados no Ginásio Pernambucano, com a apresentação das teses de Hilton Sette, sobre a Divisão de Pernambuco em regiões naturais e, em seguida, com um estudo da geografia urbana da cidade de Pesqueira; de Gilberto Osório de Andrade, com uma tese sobre morfologia litorânea na região da ilha de Itamaracá e, em 1958, com a tese de Manuel Correia de Andrade, intitulada $O$ Vale do Siriji: um estudo de geografia regional, defendida em 1961. Nesta tese o autor demonstra uma grande preocupação com a erosão antrópica, com as transformações no hábitat e com o crescimento da indústria açucareira no Vale do Siriji. No Instituto de Educação, que era uma casa inovadora e onde, nos anos de 1920, iniciou-se o estudo da Sociologia no Brasil, com a criação de cadeira dirigida e ministrada por Gilberto Freyre, houve concurso para a cátedra de Geografia do Brasil, cujo candidato único foi o jornalista e poeta Mauro Mota, com uma tese sobre o Cajueiro Nordestino. Mota, que lecionava geografia em vários estabelecimentos de ensino médio, já publicara um livro sobre Geografia literária e um outro em que analisava as modificações paisagísticas no Sertão e Agrestes nordestinos, em que salientava a tendência da formação de cidades nas encruzilhadas, tema que seria depois estudado por Rachel Caldas Lins, em livro intitulado de Cidades gasolina.

\section{A implantação da Associação dos Geógrafos Brasileiros (AGB) em Pernambuco e o desenvolvimento das atividades de pesquisas do campo}

Os anos de 1950 foram bastante favoráveis ao desenvolvimento dos estudos geográficos em Pernambuco, devido à implantação das Faculdades de Filosofia, Ciências e Letras, inicialmente como faculdades particulares, a exemplo das Dorotéias, em 1939, e a dos Jesuítas, em 1943, seguidas, em 1950, da Faculdade Oficial, estadual. Com elas, criava-se, também, na então Universidade do Recife, atual Federal de Pernambuco, uma faculdade, não confessional. E foi aí que os professores Gilberto Osório de Andrade, titular de Geografia Física, e Mário Lacerda de Mello, da área de Geografia Humana, passaram a complementar o ensino em sala de aula, com os trabalhos de pesquisa de campo. Nesses trabalhos, contaram com a colaboração de seus assistentes, Manuel Correia de Andrade e Hilton Sette, e de outros professores de ciências sociais, como o historiador e antropólogo Estevão Pinto, o psicólogo social Silvio Rabelo e o antropólogo José Heskett Lavareda. Excursões didáticas e de pesquisas foram realizadas na Serra Negra, "ilha" ecológica no Sertão pernambucano, das quais resultaram três monografias; com o apoio do professor Estevão Pinto foram feitos estudos na área de Águas Belas, visando a uma aproximação científica com os índios Fulni-ô.

Em 1952, a AGB - Associação de Geógrafos Brasileiros, fundada em São Paulo, em 1934, pelo professor Pierre Defonttaines, resolveu realizar sua Assembléia Geral, anual, na Paraíba, iniciando o conclave em Campina Grande e encerrando o mesmo em João Pessoa. Os dois principais diretores dessa associação, os professores da USP João Dias da Silveira e Aziz Ab'Saber, vieram ao Recife para convocar os geógrafos locais a participarem da assembléia. Alguns professores de geografia participaram do conclave, como Gilberto Osório de Andrade, Mário Lacerda de Mello, Hilton Sette e Tadeu Rocha, e, ao voltarem ao Recife, fundaram o núcleo estadual da AGB. No ano seguinte, em Assembléia Geral, realizada em Cuiabá, o professor Mário Lacerda de Mello foi eleito sócio efetivo da AGB, habilitando-se a chegar à presidência da Associação em 1954, em Congresso realizado em Ribeirão Preto, tornando a participação pernambucana cada vez mais forte. O XVII Congresso Internacional de Geografia, realizado no Rio de Janeiro, em 1956, possibilitou que, em 1959, outro 
pernambucano, Gilberto Osório de Andrade, fosse eleito para a presidência da Associação e, em 1961, em Londrina, a presidência voltasse a Pernambuco, com Manuel Correia de Andrade. Os presidentes pernambucanos realizaram suas assembléias gerais, respectivamente, em Garanhuns, em 1955, em Mossoró, em 1960, e em Penedo, em 1962.

Daí em diante, foram numerosos os associados de Pernambuco que ocuparam cargos de direção no órgão máximo da geografia brasileira, provocando a formação de grupos de pesquisa na Universidade.

Outros passos seriam dados na produção da geografia e na formação de geógrafos no Recife; entre eles podemos salientar o início dos cursos de pós-graduação, a estreita colaboração do Departamento de Ciências Geográficas com outros departamentos ligados às ciências da Terra e às ciências humanas e sociais, a colaboração com trabalhos desenvolvidos pelo Instituto, depois Fundação Joaquim Nabuco, em pesquisas sobre problemas fundamentais da região, a colaboração com a Sudene, a criação do curso de pós-graduação, stricto sensu, em nível de mestrado, no próprio departamento e, posteriormente, do curso de gestão ambiental, a intensificação das relações de colaboração com professores de outros estados do Brasil e do exterior, sobretudo franceses e norte-americanos.

Temas teórico-metodológicos e problemas regionais foram debatidos por geógrafos pernambucanos, tornando-se objetos de dissertações de mestrado, bem como a colaboração de geógrafos dos cursos de doutorado em outras universidades, coma a USP, a UFRJ, a Unesp (Rio Claro), a UFSE, e, no exterior, sobretudo em Paris. A visita de eminentes geógrafos estrangeiros, ministrando cursos ou fazendo conferências, como Francis Ruellan, Pierre Mombeig, Michel Rochefort, Philliponeau, entre outros, foi da maior importância para a geografia local.

Em colaboração com a Fundação Joaquim Nabuco, os geógrafos, sob a direção de Gilberto Osório de Andrade e equipe, que reunia professores e alunos do curso de geografia, ocuparam-se por cerca de quatro anos - entre 1954 e 1961 -, com estudos sobre a poluição dos cursos d'água da região da Mata nos estados do Rio
Grande do Norte, da Paraíba, de Pernambuco, de Alagoas, produzindo cerca de cinco monografias, verdadeiramente pioneiras, que materializaram trabalhos de campo preconizados, nos anos de 1930, por Gilberto Freyre e Vasconcelos Sobrinho.

Também na Fundação Joaquim Nabuco foram realizados trabalhos interdisciplinares sobre migrações para o Recife e para Manaus, quando o setor geográfico esteve sob a direção de Mário Lacerda de Mello. O estudo do Recife foi dirigido pelo sociólogo Levy Cruz, contando com a participação do economista Paulo Maciel, do geógrafo Mário Lacerda de Mello e do estatístico e demógrafo Antônio Carolino Gonçalves.

De importância fundamental foi a colaboração desenvolvida com a Sudene, quando o diretor de departamento de política espacial era o geógrafo Carlos José Caldas Lins que, especialista em estudos regionais, passou a desenvolver pesquisas de campo e produzir ensaios em colaboração com várias universidades do Nordeste. As pesquisas, que envolviam professores de geografia e de outros departamentos e alunos de graduação e pós-graduação, produziram ensaios sobre as chamadas regiões agrárias, definidas no livro Regionalização agrária do Nordeste, de 1978, como, entre outras, "Agrestes", "Sertão Norte", "Meio Norte", "Sertão Sul", "Área do Sistema Canavieiro" etc. e, em seguida, estudos de regiões urbanas, como as áreas de Teresina, Ilhéus-Itabuna e Aracaju. As monografias publicadas foram escritas por Gilberto Osório de Andrade, Mário Lacerda de Mello, Manuel Correia de Andrade, Rachel Caldas Lins, Diva de Andrade Lima, Marlene Maria Silva, José Alexandre Filizola Diniz, Silvio Bandeira de Melo etc. Representavam uma fotografia do Nordeste com os seus problemas e com as possíveis soluções para os mesmos, como o do latifúndio, da exploração extrativa vegetal, da agro indústria canavieira, da monocultura cacaueira, da modernização da pecuária, da pequena agricultura, do contraste entre os brejos e a caatinga e da caracterização da região do Agreste e das Serras Frescas. Acreditamos que este conjunto de monografias seja uma das principais contribuições dadas pela Sudene ao conhecimento da região que pretendia desenvolver.

A geografia pernambucana, porém, não apresenta uma unidade de pensamento; em seu 
seio chocam-se idéias e posições divergentes, como as que dividiram os geógrafos, na década de 1970, com o surgimento da chamada geografia teorética ou quantitativa ou as discussões sobre a própria natureza da Geografia, quando se debatia se ela devia estar aberta a influências teóricometodológicas e ao afluxo dos princípios das ciências sociais em geral ou se deveria defender o que se chamava de "geograficidade", ou, ainda, se deveria ser mantida a unidade da geografia ou separá-la em dois campos, o da geografia física e o da geografia humana.

Esta divisão era de grande importância porque permitia que o geógrafo se especializasse em capítulos de cada uma das duas grandes divisões, os quais se tornam cada vez mais extensos e autônomos, dando margem a novos ramos do conhecimento, como a Geomorfologia, em grande parte geológica, a Climatologia, em grande parte Meteorológica, a Biogeografia, ligada à Biologia, ao passo que a Geografia Humana dos franceses era a Geografia Econômica dos anglo-saxões e a Geografia Cultural dos alemães; também se infiltrava na Demografia, ao estudar as populações, nas ciências agrárias, ao estudar a agricultura e a pecuária, e no urbanismo, ao fazer a análise das cidades. Ainda estava ligada à Ciência Política e às Relações Internacionais quando abordava temas políticos, chegando à Geografia Política e à Geopolítica. Assim, nesse universo de conhecimentos, a Geografia tinha que cultivar a interdisciplinaridade e realizar uma união entre a unidade e a diversidade, sem atingir um caráter enciclopédico.

Além dessa busca permanente da unidade, os geógrafos pernambucanos ou estudiosos da problemática pernambucana e nordestina, tinham que dar a maior atenção aos problemas regionais, em face, inclusive, da perda de importância política de Pernambuco e do Nordeste no contexto brasileiro. Defrontavam-se também com problemas ligados à própria evolução do conhecimento científico, quando tiveram que abandonar a idéia de que a geografia era uma maneira de reunir informações ligadas à superfície da Terra, passando a descrever e interpretar as paisagens existentes e os problemas advindos das condições naturais e a ação do homem. A contribuição de Josué de Castro foi enorme nesse sentido, porque, como médico, ele trouxe para reflexão geográfica o problema da alimentação. Alguns geógrafos, porém, preferiam preservar a geografia de preocupações políticas e sociais, consideradas pertencentes à área da sociologia e da ciência política, defendendo um falso principio de "geograficidade". Assim, eram feitos estudos de geografia agrária levando em conta a exploração da terra em face da influência de fatores como a localização geográfica, o clima, o relevo, o solo e as associações vegetais, e ignorava a importância do mercado para os mais diversos produtos, os sistemas histórico-sociais de exploração da terra, as políticas governamentais, os sistemas de governo etc. E isso era feito em nome de uma chamada geograficidade e dizendo-se com base nos ensinamentos de Vidal de la Blache, esquecendo que o famoso geógrafo francês escreveu um livro de geopolítica, intitulado de La France de l'Est.

Dentro dessa linha teórico-metodológica, havia autores que se voltavam para os problemas do meio ambiente, como os agrônomos biogeógrafos Vasconcelos Sobrinho, Dárdano de Andrade Lima e Sérgio Tavares; e havia os que, com uma formação dialética, procuravam ver as direções políticas e sociais, como ocorria, no Rio de Janeiro, com Orlando Valverde, e em Pernambuco, com Manuel Correia de Andrade, que, ao publicar seu livro A terra e o bomem do Nordeste, recebeu, do Departamento de Geografia da UFPE, uma forte oposição e criticas, embora tivesse sido muito bem recebido por antropólogos e sociólogos de nossa Universidade e de outros estados, inclusive da USP. Ali, ele foi muito bem aceito no departamento de Geografia, da mesma forma que o seu livro seguinte Paisagens e problemas do Brasil.

Nos anos de 1970, tivemos um novo embate, quando o governo militar estimulou trabalhos de matematização da geografia, sobretudo no IBGE e na Unesp - Rio Claro, visando a despolitizar, diziam, os estudos científicos. O Departamento de Geografia manteve-se à margem desse movimento, mesmo no período difícil em que ele controlou a Associação dos Geógrafos Brasileiros, assim como se manteve um pouco à margem quando veio a reação, partida de São Paulo e que foi chamada de Geografia Crítica. Os dois grupos mantiveram intensa atividade na área de publicações. Na época, Milton Santos organizou o livro Novos rumos da geografia brasileira, 
com a colaboração de diversos autores, alguns pernambucanos.

Bastante significativa foi a criação do curso de Mestrado em Geografia na UFPE, em 1977, o terceiro deste nível criado no país, que procurou, durante alguns anos, desenvolver uma filosofia crítica e comprometê-lo com a análise dos problemas nordestinos. Fato que não impediu o ingresso de estudantes oriundos dos mais diversos estados do Brasil, desde o Acre até o Rio Grande do Sul, e que deu origem a dissertações as mais diversas, como se pode constatar em publicação realizada em 1996, onde são indicados os títulos de cem trabalhos, em que as preferências estão apontadas para temas, como problemas ambientais, geografia agrária, relações cidade campo, questões urbanas, dando grande ênfase aos problemas nordestinos.

As preocupações com a problemática nacional e regional e com os perigos advindos com a destruição do meio ambiente, em face da deliberações do Clube de Roma e das Convenções de Estocolmo (1972), do Rio de Janeiro (1992), de Johanesburgo, levaram a UFPE a implantar, em colaboração com outras universidades do Brasil e de Portugal, cursos de pós-graduação dedicados ao estudo dos problemas ambientais e de combate em favor do chamado desenvolvimento sustentável. Nessa linha foi criado, em 1997, o Curso de Mestrado em Gestão e Políticas Ambientais, sob a direção do professor Joaquim Correia Xavier de Andrade Neto, tendo como vice a professora Maria do Carmo Sobral. Curso que, apesar de envolver vários departamentos da Universidade, funciona no Departamento de Ciências Geográficas, sendo olhado com a maior dedicação e carinho pela diretora do $\mathrm{CFCH}$, a geógrafa e professora Edvânia Torres.

O grupo de geógrafos pernambucanos vem sendo enriquecido com o ingresso de novos mestres e doutores que seguem posições teóricas e metodológicas diferentes e mantêm o nome do Estado e da Universidade em nível elevado, salientando, também, o relacionamento que vem sendo mantido com outros departamentos e com outras universidades do país e do exterior, assim como com órgãos federais, como o CNPq, a Capes, a Finep etc. e estaduais como a Facepe. 


\section{A GEOGRAFIA NO CONTEXTO DAS CIÊNCIAS SOCIAIS EM PER- NAMBUCO}

Manuel Correia de Andrade

Palavras-chave: Geografia do Brasil; Geografia em Pernambuco; Bibliografia; História.

Neste texto inédito Manuel Correia de Andrade apresenta um traçado histórico do processo de transformação do campo da Geografia no Brasil, tratando, em particular, do estado de Pernambuco. O autor procura delimitar no espaço e no tempo o que seria a Geografia e quais as relações por ela mantidas com as várias ciências naturais e sociais que lhe estão próximas e que, muitas vezes, se interpenetram. Analisa, então, os primórdios desse processo no início do século XX, com estudos, nem sempre considerados geográficos, passando por momentos cruciais como a fundação da Associação dos Geógrafos Brasileiros na década de 1930, o florescimento do campo nos anos de 1950 e o impacto do golpe militar de 1964 na área dos estudos geográficos.

\section{GEOGRAPHY IN THE CONTEXT OF THE SOCIAL SCIENCES IN PERNAMBUCO}

Manuel Correia de Andrade

Keywords: Brazilian geography; Geography in Pernambuco; Bibliography; History.

In this unpublished paper Manuel Correia de Andrade presents a historical tracing on the transforming process in the field of geography in Brazil, dealing especially with the state of Pernambuco. The author tries to delimitate both in space and time what geography would be, as well as its relations with the various natural and social sciences that are close to or interpenetrated within. He analyzes, then, the commencements of such process in the beginning of the twentieth century with studies, not always considered geographical, passing through crucial moments such as the foundation of the Brazilian Association of Geographers in the 1930s, the flourishing of the field in the 1950s, and the impact of the military coup d'état of 1964 in the area of geographic studies.

\section{LA GEOGRAPHIE DANS LE CON- TEXTE DES SCIENCES SOCIALES AU PERNAMBOUC}

Manuel Correia de Andrade

Mots-clés: Géographie du Brésil; Géographie au Pernambouc; Bibliographie; Histoire.

Dans ce texte inédit, Manuel Correia de Andrade présente un tracé historique du processus de transformation dans le domaine de la géographie du Brésil, en abordant, en particulier, l'état du Pernambouc. L'auteur cherche à délimiter dans l'espace et dans le temps ce que serait la géographie et les rapports qu'elle maintien avec plusieurs sciences naturelles et sociales qui lui sont proches et qui, souvent, s'interpénètrent. Il analyse, ensuite, les origines de ce processus au début du XX siècle, avec des études qui ne sont pas toujours considérées comme géographiques, en passant par des moments cruciaux comme la fondation de l'Association des Géographes Brésiliens dans les années 1930, le déploiement de ce domaine dans les années 1950 et l'impact du coup militaire de 1964 dans le cadre des études géographiques. 